\title{
Prognostic Nutritional Index and its Dynamics After Curative Treatment are Independent Prognostic Factors on Survival in Non-Metastatic Nasopharyngeal Carcinoma
}

Ahmet Küçükarda ( $\nabla$ ahmetkucukarda22@gmail.com )

Trakya University Faculty of Medicine: Trakya Universitesi Tip Fakultesi https://orcid.org/0000-00017399-2360

\section{Bülent Erdoğan}

Trakya University Faculty of Medicine: Trakya Universitesi Tip Fakultesi

\section{Ali Gökyer}

Trakya University Faculty of Medicine: Trakya Universitesi Tip Fakultesi

\section{Sezin Sayın}

Trakya University Faculty of Medicine: Trakya Universitesi Tip Fakultesi İvo Gökmen

Trakya University Faculty of Medicine: Trakya Universitesi Tip Fakultesi

\section{Erkan Özcan}

Trakya University Faculty of Medicine: Trakya Universitesi Tip Fakultesi

\section{Muhammet Bekir Hacıoğlu}

Trakya University Faculty of Medicine: Trakya Universitesi Tip Fakultesi

\section{Sernaz Uzunoğlu}

Trakya University Faculty of Medicine: Trakya Universitesi Tip Fakultesi

\section{İfan Çiçin}

Trakya University Faculty of Medicine: Trakya Universitesi Tip Fakultesi

\section{Research Article}

Keywords: nasopharyngeal cancer, prognostic nutritional index, survival

Posted Date: June 4th, 2021

DOl: https://doi.org/10.21203/rs.3.rs-429555/v1

License: (c) (1) This work is licensed under a Creative Commons Attribution 4.0 International License. Read Full License 
Version of Record: A version of this preprint was published at Supportive Care in Cancer on October 22nd, 2021. See the published version at https://doi.org/10.1007/s00520-021-06627-6. 


\section{Abstract}

Purpose: We aimed to identify the prognostic and predictive values of post-treatment prognostic nutritional index (PNI) and PNI dynamics in nasopharyngeal cancer patients (NPC) in this study.

Methods: 107 non-metastatic NPC patients were included. PNI was calculated by using the following formula: [10 $x$ serum albumin value $(\mathrm{gr} / \mathrm{dL})]+[0.005 \times$ total lymphocyte count (per mm3)]. ROC analysis was used for determining prognostic PNI values and univariate and multivariate statistical analyses for prognostic characterization of PNI.

Results: The statistically significant cut-off values for pre-and post-treatment PNI were 50.65 and 44.75 , respectively. Of the pre-treatment $\mathrm{PNI}$ analysis, $\mathrm{PNI} \leq 50.65$ group had shorter loco-regional recurrence-free survival (LRRFS), distant metastasis-free survival (DMFS), and overall survival (OS). Furthermore, for post-treatment PNI analysis, $\mathrm{PNI} \leq 44.75$ group had shorter LRRFS and OS. In univariate analysis, only pretreatment PNI was associated with LRRFS and DMFS, while pre-and post-treatment PNI were both associated with OS. In multivariate analysis, both PNI were independent prognostic markers for OS. In the combined analysis, pre-and post-treatment PNI, differences between the groups were statistically significant, and the PNI dynamics was an independent prognostic indicator for OS.

Conclusion: PNI is a useful, independent prognostic marker for non-metastatic NPC patients. It is used for either pre-or post-treatment patients. Furthermore, changes in pre-treatment PNI value after curative treatment is a significant indicator for OS.

\section{Introduction}

Nasopharyngeal cancer (NPC) is a rare head and neck tumor and is usually endemic in South Asia and Africa. Worldwide, there were 133.000 new cases and 80.000 recent deaths in 2020 (1). Ebstein- Barr virus (EBV) infections, the host's genetic predisposition, and environmental factors such as tobacco, alcohol, and preserved food intake are the most common etiologic factors (2). According to World Health Organization (WHO) classification, there are three histopathologic subtypes, and undifferentiated nonkeratinizing carcinoma (WHO type III) is the predominant type (3).

Due to the unsuitability of anatomical location for surgery and its chemo-radiosensitivity, radiotherapy (RT) or combined-modality therapy is the standard of care for NPC (2). The treatment depends on the tumor, node, and metastasis (TNM) stage in NPC (4). However, the most important prognostic factor is TNM staging, NPC patients with the same clinical stage have different clinical courses. There was no satisfying definition for that situation. The most likely explanation is that TNM is primarily an anatomical staging system and does not reflect the pathobiology of the tumor and clinical factors of the host. Therefore, identifying prognosis-related markers and their use in practical life may eliminate TNM staging deficiency in determining prognosis (4). 
Malnutrition is observed in $30-50 \%$ of head and neck cancer patients at the time of diagnosis because of their anatomic location and tumor-related factors. Besides, treatment may increase malnutrition with severe adverse effects (5), and it affects the immune system of the patient and promotes tumor progression and metastasis due to reducing disease resistance (6). Therefore, many studies have focused on the nutrition and immune status of the patient to predict cancer prognosis. Prognostic nutritional index (PNI) is a valuable tool to evaluate cancer patients' nutritional and immune status, and it is calculated by a formula using total lymphocyte count and serum albumin concentration (7). Many studies have shown that PNI is an important prognostic marker in various cancers (8). Some recently published studies also revealed that pre-treatment PNI is related to NPC patients' survival outcomes (920).

Although pre-treatment PNI is an excellent prognostic marker for NPC patients, there were no data about post-treatment PNI and its prognostic effect. Therefore, we performed this study to investigate the predictive role of both pre-and post-treatment PNI and evaluate its impact on oncologic outcomes according to its dynamics before and after treatment.

\section{Materials And Methods}

\section{Study design and patient's features:}

Our study was retrospective, descriptive, and cross-sectional. We examined local and locally advanced NPC patients diagnosed and followed up at the Trakya University Hospital, Department of Medical Oncology between 2005 and 2019. All patients were above 18 years old, had a biopsy-confirmed WHO type I-II or III NPC, treated with RT only or combined with chemotherapy according to the disease stage, had complete pre-and post-treatment clinical and laboratory data. Patients with metastatic disease at the time of diagnosis, recurrent NPC, confirmed hematological disorders, severe hepatic and renal failure, or any systemic infection that may affect PNI at diagnosis, and patients with low-performance scores were excluded. Totally 107 of 146 patients were included according to inclusion and exclusion criteria.

This study was conducted in compliance with the postulates of the Declaration of Helsinki and was approved by the Scientific Research Ethics Committee of Trakya University Hospital.

\section{Clinical data collection:}

We examined patients' history, signs and symptoms, laboratory and radiological examination results. Albumin was measured using an automatized chemistry analyzer (Roche Hitachi Cobas 8000, Rotkreuz, Switzerland), and lymphocyte counts were calculated using a hematology analyzer (Sysmex SE-9000,

Kobe, Japan). PNI was calculated with the following formula: $10 x$ serum albumin value ( $\mathrm{gr} / \mathrm{dL})+0.005 \mathrm{x}$ total lymphocyte count (per mm3) (7). Laboratory values that were measured one to seven days before treatment were used to calculate pre-treatment PNI. Furthermore, for post-treatment PNI, we used values assessed one month after the end of the treatment to exclude treatment-related effects. 


\section{Staging, treatment, and follow-up:}

The staging was identified by clinical examination, endoscopic evaluation and magnetic resonance imaging (MRI) of nasopharynx and neck, and positron emission computed tomography (PET-CT) or contrast computerized tomography. All patients were restaged according to the 8th edition of the American Joint Committee on Cancer system (21).

All patient's therapy was planned according to their TNM stage. While stage 1 patients were treated with only RT, stage 2 patients were treated with concomitant chemoradiotherapy (CCRT). Most of the stage 3 patients were treated with CCRT, except for larger tumors and N3 disease. All patients with stage 4a and stage 3 with large tumors and N3 nodal involvement were treated with induction or adjuvant chemotherapy CCRT.

RT was given as five days per week as a daily fraction. The total dosage was 66 to 70 Gy for primary nasopharyngeal lesions and regional lymph nodes. The concomitant regimen was cisplatin, and it was started with the first day of radiotherapy, and dosage was $40-50 \mathrm{mg} / \mathrm{m} 2$ intravenous infusion weekly.

The induction chemotherapy regimen was three cycles of Docetaxel, Cisplatin, and 5-fluorouracil (DCF); docetaxel $75 \mathrm{mg} / \mathrm{m} 2$, cisplatin $75 \mathrm{mg} / \mathrm{m} 2$ on day 1 , and 5 -fluorouracil $750 \mathrm{mg} / \mathrm{m} 2$ on days $1-4$. The adjuvant chemotherapy regimen was 3-6 course of CF; cisplatin $100 \mathrm{mg} / \mathrm{m} 2$ on day one and 5fluorouracil $1000 \mathrm{mg} / \mathrm{m} 2$ on days $1-4$. Some patients with renal failure or severe neuropathy were treated with carboplatin AUC(5-6) instead of cisplatin.

All patient's follow-up duration was defined from the diagnosis to the last examination date. Both nasopharyngeal MRI and contrasted systemic imaging with PET-CT or CT was performed to evaluate the treatment response, and they were repeated every three months for two years. And then monitorization continued six monthly to the death. Response Evaluation Criteria in Solid Tumors (RECIST) criteria were used for the evaluation of treatment response.

It was accepted as a locoregional failure if nasopharyngeal or regional nodal recurrence occurred, and if the recurrence occurred in other sides, it was considered as distant metastasis. The LRRFS and DMFS were the duration between the first day of treatment and failure day. OS was the duration between the diagnosis and the last examination or death of the patient.

\section{Statistical analysis:}

A receiver-operating characteristic $(\mathrm{ROC})$ curve analysis was performed for determining cut-off values of pre-and post-treatment PNI. Chi-square and Fisher's exact tests were used to compare categorical variables such as age, gender, T stage, $\mathrm{N}$ stage, and PNI values. We performed the log-rank test for comparing groups for LRRFS, DMFS, and OS. The proportional hazards regression model was applied to identify the best predictor variables using univariate and multivariate analyses. A $p$-value $<0.05$ was set for statistical significance. The data were analyzed with IBM SPSS Statistics 23.0 (IBM Corp., Armonk, New York, USA). 


\section{Results}

\section{Patient's characteristics:}

The median age was 52 years (range $44-60$ years). Seventy-four patients (69.2\%) were male, and 87 $(81.3 \%)$ of them had WHO type III histology. Of the 107 patients, 14 (13.1\%), 36 (33.6\%), 21 (19.6\%), and 36 (33.6\%) had T1, T2, T3, and T4 tumors, respectively. Fourteen (13.1\%), 13 (12.1\%), 55 (51.4\%), and 25 (23.4\%) had N0, N1, N2, and N3 nodal involvement, respectively. Three (2.8\%), $13(12.1 \%), 40(37.4 \%)$, and 51 (47.7\%) of them showed stage 1, 2, 3, and 4a, respectively. The median follow-up time was 50.0 months (range 21.5-84.5 months). At the date of the last follow-up day, 39 (36.4\%) patients had a locoregional recurrence, $44(41.1 \%)$ patients had distant metastasis, and $46(43 \%)$ of them died (Table 1$)$.

\section{Treatment types and response assessment:}

One hundred seven patients were treated; 9 (8.4\%) of them with RT only, $48(44.9 \%)$ with CCRT, 37 (34.6\%) with induction chemotherapy followed by CCRT, and 13 (12.1\%) with CCRT followed by adjuvant chemotherapy. Fifty-two (48.6\%), 36 (33.6\%), 5 (4.6\%), and 14 (13.1\%) had complete response (CR), partial response (PR), stable disease (SD) and progressive disease (PD) according to RECIST criteria, respectively (Table 1$)$.

\section{Cut-off values of parameters and comparison of groups:}

The median value for pre-treatment lymphocyte count, serum albumin concentration, and PNI were 1800 per mm3 (range 1320 - 2400 per mm3), $41 \mathrm{gr} / \mathrm{L}$ (range 38 - $44 \mathrm{gr} / \mathrm{L}$ ), and 51 (range 44.5 - 54.5), respectively. And for post-treatment, the values were 1090 per mm3 (range 700-1370 per mm3), $40 \mathrm{gr} / \mathrm{L}$ (range 34 - $42 \mathrm{gr} / \mathrm{L}$ ), and 45 (40.5 - 49.5), respectively (Table 1).

According to ROC analyses done for finding statistically significant PNI cut-off values, 50.65 (area under the curve (AUC):0.317, $\mathrm{P}=0.001$ ) for pre-treatment $\mathrm{PNI}$, and 44.75 (AUC:0.155, $\mathrm{P}<0.001$ ) for post-treatment PNI.

Two groups were created based on high or low PNI values. When we compared the groups according to their clinical and demographic features, for pre-treatment PNI, only age was statistically significantly higher in $\mathrm{PNI} \leq 50.65$ group $(\mathrm{p}<0.01)$. There were no differences between other parameters. However, for post-treatment PNI, N3 nodal involvement and disease stage 4a were more common in PNI $\leq 44.75$ group $(p=0.04$ and 0.02 , respectively). According to the treatment response assessment between PNI groups, there were no differences between pre-treatment PNI groups. For post-treatment PNI groups, CR was much more than non-CR in PNI>44.75 group, and this was statistically significant $(p<0.01)($ Table 2$)$.

\section{Survival analysis:}

The 5-year LRRFS, DMFS, and OS rates were $80.4 \%, 82.6 \%$, and $78.2 \%$, respectively. Ten-year LRRFS, DMFS, and OS rates were $68.2 \%, 76.2 \%$, and $56.4 \%$, respectively. For the whole treatment population, 
median LRRFS was 15.3 months (95\% Cl: 8.9-21.7 months), median DMFS was 11.8 months (95\% Cl: $5.2-$ 18.4 months), and median OS was 121 months (95\% Cl: 56.2-185.9 months).

Of the pre-treatment PNI analysis, median LRRFS was 8.9 months (95\% Cl: $6.4-11.5$ months) in $\mathrm{PNI} \leq 50.65$ group while it was 28.3 months ( $95 \% \mathrm{Cl}$ : $16.1-40.5$ months) in $\mathrm{PNI}>50.65$ group $(\mathrm{p}<0.01)$. Median DMFS was 8.9 months (95\% Cl: 6.3-11.6 months) in PNI $\leq 50.65$ group while it was 19.2 months (95\% Cl: 6.8-31.5 months) in PNI>50.65 group ( $p<0.01$ ). Median OS was 46.9 months ( $95 \% \mathrm{Cl}$ : $26.4-67.5$ months) in PNI $\leq 50.65$ group, while it was not assessed (NA) in PNI $>50.65$ group $(p<0.01)$ (Figure 1).

Of the post-treatment PNI analysis, median LRRFS was 11.5 months (95\% Cl: $5.4-17.6$ months) in $\mathrm{PNI} \leq 44.75$ group while it was 28.3 months (95\% Cl: 9.0-47.6 months) in PNl $>44.75$ group ( $\mathrm{p}=0.04)$. Median DMFS was 11.5 months (95\% Cl: 1.7-21.3 months) in PNI 444.75 group while it was 12.0 months (95\% Cl: 0.9-26.2 months in PNI>44.75 group ( $p>0.05$ ). Median OS was 49.9 months (95\% Cl: $26.8-67.0$ months) in $\mathrm{PNI} \leq 44.75$ group, while it was not assessed (NA) in PNI $>44.75$ group $(p<0.01)$ (Figure 1$)$.

\section{Univariate and multivariate analyses:}

In the univariate analysis, N category, TNM stage, treatment type, treatment response, and pre-treatment PNI were associated with LRRFS. In contrast, only pre-treatment PNI was associated with DMFS. In the multivariate analyses for LRRFS and DMFS, only pre-treatment PNI was statistically significant $(p<0.01$ and $p=0.04$, respectively) (Table 3 ).

In the univariate analysis of OS, age, histologic subtype, T category, N category, TNM stage, treatment response, pre-treatment $\mathrm{PNI}$, and post-treatment PNI were both associated with survival. The multivariate analysis for OS, T category, $\mathrm{N}$ category, treatment response, pre-treatment $\mathrm{PNI}$, and post-treatment PNI was statistically significant (Table 4).

As seen in whole multivariate analyses pre-treatment, PNI was an independent prognostic factor for worse LRRFS, DMFS, and OS. In contrast, post-treatment PNI was the only independent prognostic factor for OS (Table 4).

\section{Combined prognostic analysis of PNI values:}

The patients were examined by dividing into four groups for the combined prognostic value of pre-and post-treatment PNI: patients with high pre-treatment and high post-treatment PNI were defined as group 1, low pre-treatment and high post-treatment PNI as group 2, high pre-treatment and low post-treatment PNI as group 3, and low pre-treatment and low post-treatment PNI as group 4. Differences between the groups were statistically significant $(p<0.01)$. When the univariate analysis was done to find the prognostic effect of groups according to select group 4 as an indicator, group 1,2 and 3 had an HR of 0.12 ( $95 \% \mathrm{Cl} 0.05$ $0.30, \mathrm{p}<0.01), 0.18$ (95\% Cl 0.06-0.52, $\mathrm{p}<0.01)$, and 0.48 (95\% Cl 0.23-0.99, $\mathrm{p}=0.047$ ), respectively. As in the analysis, group 2 had a statistically significant effect on prognosis like group 1 (Figure 2). 


\section{Discussion}

To the best of our knowledge, this study was the first study to investigate the prognostic role of posttreatment PNI and its combined analysis with pre-treatment PNI in local and locally advanced NPC patients. One hundred seven patients were examined and evaluated in this study, and it revealed that post-treatment PNI was statistically significantly associated with poor prognosis in the study population. Besides determining a predictive value of post-treatment PNI, our data also demonstrated the dynamics of PNI after curative treatment had an independent association with survival.

It had been widely accepted that the systemic inflammatory response and nutritional status were essential regulators in oncogenesis (4). The primary purpose of PNI is to evaluate the effect of these regulators. There were ten research articles and two meta-analyses about the prognostic effect of PNI in NPC patients. All of them were retrospective studies and used only pre-treatment PNI values. Five of them included metastatic NPC patients that might change PNI status. In the other five studies about local and locally advanced NPC, the PNI cut-off was between 45.45 and 55, respectively. Three of these five studies were from South Asia, while two of them were from Turkey. Furthermore, two of them used only univariate analysis (9-20). Our study had a retrospective design, included only local and locally advanced NPC patients; the PNI cut-off was 50.65 for pre-treatment and 44.75 for post-treatment. We used multivariate analysis for prognostic significance of PNI.

To compare the two Turkish population studies with our article, in the first one written by Gundog $\mathrm{M}$ et al., 95 locally advanced NPC patients were included. Treatment of the whole population was only CCRT; pretreatment PNI cut-off was 45.45. According to Cox regression analysis, there was no relationship between $\mathrm{PNI}$ and LRRFS and DMFS. Only in univariate analysis for OS, PNI had a statistically significant association, but not proven by multivariate analysis (15). In the second study, which was conducted by Topkan E et al., 154 locally advanced NPC patients who had received CCRT incorporated. Pre-treatment PNI cut-off was rounded as 51. Univariate and multivariate analyses showed that low pre-treatment PNI values were associated with reduced LRRFS, DMFS, and OS (17). A part of our study was to evaluate pretreatment PNI as a prognostic factor, as these two pieces of research did. We found that low pretreatment PNI values $(\leq 50.65)$ had shorter LRRFS, DMFS, and OS than patients with high PNI. In univariate and multivariate analyses, it was an independent prognostic indicator for all.

Our hypothesis evaluated the prognostic effect of the post-treatment PNI and PNI dynamics after curative treatment. There was no study about post-treatment PNI and its prognostic effect on survival of any tumor in literature. Moreover, only one research article about PNI dynamics in metastatic castrationresistant prostate cancer patients was treated with abiraterone acetate (AA). This study showed that elevation of PNI level during the first month of AA treatment was statistically significantly correlated with OS (22). Our study demonstrated that post-treatment PNI and PNI values change after curative treatment (PNI dynamics) had a statistically significant association with OS as pre-treatment PNI. When we looked at PNI dynamics changes before and after treatment, patients in group 2 had low pre-treatment PNI values, but after treatment, their PNI values were high. This group has a survival nearly group 1 , which 
included pre-and post-treatment high PNI values. This situation showed us that dynamic changes in PNI were more critical than pre-treatment evaluation only.

There were some limitations in our present study. First, this was a retrospective study performed in a single oncology center. Thus, this might be cause selection bias for the patient population. Second, we could not evaluate supportive nutritional care for patients during the treatment period because of largely missing data in patients' files. Hence, further large-scale multi-center prospective study is required to validate the prognostic impact of PNI and its dynamics in NPC patients.

\section{Conclusion}

This study demonstrated that PNI is a useful, independent prognostic marker for local and locally advanced NPC patients, either pre-or post-treatment calculated. Furthermore, changes in pre-treatment $\mathrm{PNI}$ value after curative treatment is a statistically significant indicator for OS. PNI is cost-effective and easy to evaluate from laboratory measures, which are routinely performed in patients. The combined use of PNI and PNI dynamics with the TNM staging system can guide clinicians in predicting survival and providing more individualized treatment approaches for NPC patients.

\section{Declarations}

\section{Funding}

There is no financial support in this study.

\section{Conflict of Interest}

The authors of this manuscript declare no relationships with any companies, whose products or services may be related to the subject matter of the article.

\section{Availability of data and material}

Information provided in the literature and personal experience.

\section{Code availability}

N/A

\section{Authors' contributions}

$A K, A G, S E$ : Writing - original draft, BE, MBH, SU Writing - review \& editing, AK, AG, IG, EK: Data curation, Investigation. $\mathrm{BE}, \mathrm{MBH}, \mathrm{SU}$, iç: Supervision.

\section{Consent to participate}


$\mathrm{N} / \mathrm{A}$

\section{Consent for publication}

N/A

\section{Ethical approval}

Institutional Review Board approval was obtained. All procedures performed in studies involving participants were in accordance with the ethical standards of the institutional and/or national research committee and with the 1964 Helsinki declaration and is later amendments or comparable ethical standards.

\section{References}

1. https://gco.iarc.fr/today/data/factsheets/cancers/4-Nasopharynx-fact-sheet.pdf. Accessed 25 December 2020.

2. Chua MLK, Wee JTS, Hui EP, Chan ATC. Nasopharyngeal carcinoma. Lancet. 2016 Mar 5;387(10022):1012-1024.

3. Barnes L, Eveson JW, Reichart P, Sidransky D. Pathology and Genetics of Head and Neck Tumours. In: World Health Organization Classification of Tumors, IARC Press, Lyon 2005.

4. Pan JJ, Ng WT, Zong JF, et al. Proposal for the 8th edition of the AJCC/UICC staging system for nasopharyngeal cancer in the era of intensity-modulated radiotherapy. Cancer. 2016 Feb $15 ; 122(4): 546-58$.

5. Kono T, Sakamoto K, Shinden S, Ogawa K. Pre-therapeutic nutritional assessment for predicting severe adverse events in patients with head and neck cancer treated by radiotherapy. Clin Nutr. 2017 Dec;36(6):1681-1685.

6. Chandra RK. Nutrition and the immune system: an introduction. Am J Clin Nutr. 1997 Aug;66(2):460S-463S.

7. Onodera T, Goseki N, Kosaki G (1984) Prognostic nutritional index in gastrointestinal surgery of malnourished cancer patients. Nihon Geka Gakkai Zasshi 85:1001-1005.

8. Sun K, Chen S, Xu J, Li G, He Y. The prognostic significance of the prognostic nutritional index in cancer: a systematic review and meta-analysis. J Cancer Res Clin Oncol. 2014 Sep;140(9):1537-49.

9. Du XJ, Tang LL,Mao YP, et al.Value oftheprognosticnutritional index and weight loss in predicting metastasis and long-term mortality in nasopharyngeal carcinoma. J. Transl Med 2015;13.

10. Wei GB, Lu YY, Liao RW, et al. Prognostic nutritional index predicts prognosis in patients with metastatic nasopharyngeal carcinoma. Onco Targets Ther. 2016 Sep 28;9:5955-5961.

11. Yang L, Xia L, Wang Y, et al. Low Prognostic Nutritional Index (PNI) Predicts Unfavorable Distant Metastasis-Free Survival in Nasopharyngeal Carcinoma: A Propensity Score-Matched Analysis. PLoS One. 2016 Jul 11;11(7):e0158853. 
12. Miao J, Xiao W, Wang L, et al. The value of the Prognostic Nutritional Index (PNI) in predicting outcomes and guiding the treatment strategy of nasopharyngeal carcinoma (NPC) patients receiving intensity-modulated radiotherapy (IMRT) with or without chemotherapy. J Cancer Res Clin Oncol. 2017 Jul;143(7):1263-1273.

13. He Q, Chen L, Huang YC, et al. Correlation of pretreatment nutritional index in blood of nasopharyngeal carcinoma patients with prognosis before radio- chemotherapy. Chin J Clin Lab Sci 2018;36(3):182-5.

14. Oei RW, Ye L, Kong F, et al. Prognostic value of inflammation-based prognostic index in patients with nasopharyngeal carcinoma: a propensity score matching study. Cancer Manag Res. 2018 Aug 17; 10:2785-2797.

15. Gundog M, Basaran H. Pretreatment low prognostic nutritional index and low albumin-globulin ratio are predictive for overall survival in nasopharyngeal cancer. Eur Arch Otorhinolaryngol. 2019 Nov;276(11):3221-3230.

16. He Q, Huang Y, Wan G, et al. A novel prognostic marker based on risk stratification with prognostic nutritional index and age for nasopharyngeal carcinoma patients who received neoadjuvant chemotherapy. Biomark Med. 2019 Aug;13(12):1013-1023.

17. Topkan E, Yucel Ekici N, Ozdemir Y, et al. Baseline Low Prognostic Nutritional Index Predicts Poor Survival in Locally Advanced Nasopharyngeal Carcinomas Treated With Radical Concurrent Chemoradiotherapy. Ear, nose, \& throat journal. 2019:145561319856327.

18. Zeng X, Liu G, Pan Y, Li Y. Prognostic Value of Clinical Biochemistry-Based Indexes in Nasopharyngeal Carcinoma. Front Oncol. 2020 Mar 6;10:146.

19. Tang M, Jia Z, Zhang J. The prognostic role of prognostic nutritional index in nasopharyngeal carcinoma: A systematic review and meta-analysis. Int J Clin Oncol. 2020 Oct 7.

20. Tu X, Ren J, Zhao Y. Prognostic value of prognostic nutritional index in nasopharyngeal carcinoma: $A$ meta-analysis containing 4511 patients. Oral Oncol. 2020 Nov;110:104991.

21. Lee AWM, Lydiatt WM, Colevas AD, et al. Nasopharynx. In: AJCC Cancer Staging Manual, 8th ed, Amin MB (Ed), Springer, New York 2017. p.103.

22. Fan $L$, Wang $X$, Chi $C$, et al. Prognostic nutritional index predicts initial response to treatment and prognosis in metastatic castration-resistant prostate cancer patients treated with abiraterone. Prostate. 2017 Sep;77(12):1233-1241.

\section{Tables}

Table 1. Characteristics and demographic features of study subjects. 


\begin{tabular}{|c|c|}
\hline & $\begin{array}{l}\text { All patients } \\
(\mathrm{n}=107)\end{array}$ \\
\hline \multicolumn{2}{|l|}{ Age, years, $\mathrm{n}(\%)$} \\
\hline Median (IQR) & $52(44-60)$ \\
\hline \multicolumn{2}{|l|}{ Gender, n(\%) } \\
\hline Female & $33(30.8)$ \\
\hline Male & $74(69.2)$ \\
\hline \multicolumn{2}{|c|}{ Histologic type, n(\%) } \\
\hline WHO Type I & $6(5.6)$ \\
\hline WHO Type II & $14(13.1)$ \\
\hline WHO Type III & 87 (81.3) \\
\hline \multicolumn{2}{|l|}{ T category, n(\%) } \\
\hline T1 & $14(13.1)$ \\
\hline T2 & $36(33.6)$ \\
\hline T3 & $21(19.6)$ \\
\hline T4 & $36(33.6)$ \\
\hline \multicolumn{2}{|l|}{$\mathrm{N}$ category, n(\%) } \\
\hline NO & $14(13.1)$ \\
\hline N1 & $13(12.1)$ \\
\hline N2 & $55(51.4)$ \\
\hline N3 & $25(23.4)$ \\
\hline \multicolumn{2}{|l|}{ TNM stage, n(\%) } \\
\hline Stage 1 & $3(2.8)$ \\
\hline Stage 2 & $13(12.1)$ \\
\hline Stage 3 & $40(37.4)$ \\
\hline Stage $4 a$ & $51(47.7)$ \\
\hline
\end{tabular}




\begin{tabular}{|ll|}
\hline & $\begin{array}{l}\text { All patients } \\
(\mathrm{n}=107)\end{array}$ \\
\hline Treatment type, $\mathrm{n}(\%)$ & \\
RT & $9(8.4)$ \\
CRT & $48(44.9)$ \\
Induction Cht- CRT & $37(34.6)$ \\
CRT - Adjuvant Cht & $13(12.1)$ \\
\hline Treatment response, $\mathrm{n}(\%)$ & \\
\hline Complete response & $52(48.6)$ \\
Partial response & $36(33.6)$ \\
Stabil disease & $5(4.6)$ \\
Progressive disease & $14(13.1)$ \\
\hline Pre-treatment lymphocyte (per mm3), $\mathrm{n}(\%)$ & \\
\hline Median (IQR) & $1800(1320-2400)$ \\
\hline Pre-treatment albumin (gr/L), $\mathrm{n}(\%)$ & \\
\hline Median (IQR) & $41(38-44)$ \\
\hline Pre-treatment PNI, $\mathrm{n}(\%)$ & $51(44.5-54.5)$ \\
\hline Median (IQR) & $45(40.5-49.5)$ \\
\hline Post-treatment lymphocyte (per mm3), $\mathrm{n}(\%)$ & \\
\hline Median (IQR) & \\
\hline Post-treatment albumin (gr/L), $\mathrm{n}(\%)$ & $(700-1370)$ \\
\hline Median (IQR) & \\
\hline
\end{tabular}

Table 2. Comparison of patients characteristics between the groups. 


\begin{tabular}{|c|c|c|c|c|c|c|}
\hline \multirow[b]{3}{*}{ Parameters } & \multicolumn{3}{|c|}{ Pre-treatment } & \multicolumn{3}{|c|}{ Post-treatment } \\
\hline & $\mathrm{PNI} \leq 50.65$ & $\mathrm{PNI}>50.65$ & $P$ & $\mathrm{PNI} \leq 44.75$ & $\mathrm{PNI}>44.75$ & $P$ \\
\hline & $n(\%)$ & $n(\%)$ & Value & $\mathrm{n}(\%)$ & $n(\%)$ & value \\
\hline \multicolumn{7}{|l|}{ Age } \\
\hline$\leq 52$ & $16(31.4)$ & 38 (67.9) & $<0.01$ & $22(42.3)$ & 32 (58.2) & 0.12 \\
\hline$>52$ & $35(68.6)$ & $18(32.1)$ & & $30(57.7)$ & $23(41.8)$ & \\
\hline \multicolumn{7}{|l|}{ Gender } \\
\hline Female & $14(27.5)$ & 19 (33.9) & 0.53 & $15(28.8)$ & 18 (32.7) & 0.68 \\
\hline Male & 37 (72.5) & $37(66.1)$ & & 37 (71.2) & 37 (67.3) & \\
\hline \multicolumn{7}{|l|}{ Histologic type } \\
\hline WHO Type $1 \& 2$ & $38(74.5)$ & 49 (87.5) & 0.13 & $15(28.8)$ & $5(9.1)$ & 0.06 \\
\hline WHO Type 3 & $13(25.5)$ & $7(12.5)$ & & 37 (71.2) & $50(90.9)$ & \\
\hline \multicolumn{7}{|l|}{ T category } \\
\hline T1-2 & 19 (37.3) & $31(55.4)$ & 0.08 & $19(36.5)$ & $31(56.4)$ & 0.06 \\
\hline T3-4 & 32 (62.7) & $25(44.6)$ & & 33 (63.5) & $24(43.6)$ & \\
\hline \multicolumn{7}{|l|}{ N category } \\
\hline N0-2 & 39 (76.5) & $43(76.8)$ & 0.99 & 35 (67.3) & $47(85.5)$ & 0.04 \\
\hline N3 & $12(23.5)$ & $13(23.2)$ & & $17(32.7)$ & 8 (14.5) & \\
\hline \multicolumn{7}{|l|}{ TNM Stage } \\
\hline Stage 1-3 & $23(45.1)$ & 33 (58.9) & 0.17 & $21(40.4)$ & 35 (63.6) & 0.02 \\
\hline Stage $4 a$ & $28(54.9)$ & $23(41.1)$ & & 31 (59.6) & $20(36.4)$ & \\
\hline \multicolumn{7}{|l|}{ Treatment } \\
\hline RT / CRT & $26(51)$ & 31 (55.4) & 0.70 & $28(53.8)$ & $29(52.7)$ & 0.99 \\
\hline IND-CRT / CRT-ADJ & $25(49)$ & $25(44.6)$ & & $24(46.2)$ & $26(47.3)$ & \\
\hline \multicolumn{7}{|l|}{ Treatment response } \\
\hline Complete response & $21(41.2)$ & $31(55.4)$ & 0.17 & $13(25)$ & 39 (70.9) & $<0.01$ \\
\hline Non-complete response & $30(58.8)$ & $25(44.6)$ & & $39(75)$ & $16(29.1)$ & \\
\hline
\end{tabular}


Table 3. Univariate and multivariate analyses for loco-regional recurrence free survival and distant metastasis free survival. 


\begin{tabular}{|c|c|c|c|c|}
\hline \multirow[b]{3}{*}{ Parameters } & \multirow{2}{*}{\multicolumn{2}{|c|}{$\begin{array}{l}\text { Univariate Analysis } \\
\text { LRRFS }\end{array}$}} & \multirow{2}{*}{\multicolumn{2}{|c|}{$\begin{array}{l}\text { Univariate Analysis } \\
\text { DMFS }\end{array}$}} \\
\hline & & & & \\
\hline & $\begin{array}{l}\text { HR (95\% Cl, Lower - } \\
\text { Upper) }\end{array}$ & $\begin{array}{l}P \\
\text { value }\end{array}$ & HR (95\% Cl, Lower - Upper) & $P$ value \\
\hline \multicolumn{5}{|l|}{ Age } \\
\hline$\leq 52$ & Referance & 0.05 & Referance & 0.14 \\
\hline$>52$ & $0.49(0.24-1.00)$ & & $1.61(0.86-3.04)$ & \\
\hline \multicolumn{5}{|l|}{ Gender } \\
\hline Female & Referance & 0.12 & Referance & 0.44 \\
\hline Male & $0.55(0.26-1.16)$ & & $1.31(0.63-2.64)$ & \\
\hline \multicolumn{5}{|l|}{ Histologic type } \\
\hline WHO Type $1 \& 2$ & Referance & 0.05 & Referance & 0.21 \\
\hline WHO Type 3 & $0.43(0.18-1.00)$ & & $0.65(0.33-1.28)$ & \\
\hline \multicolumn{5}{|l|}{ T category } \\
\hline T1-2 & Referance & 0.07 & Referance & 0.04 \\
\hline T3-4 & $1.87(0.94-3.70)$ & & $1.98(1.02$ - 3.85) & \\
\hline \multicolumn{5}{|l|}{$\mathrm{N}$ category } \\
\hline N0-2 & Referance & 0.03 & Referance & 0.40 \\
\hline N3 & $2.23(1.09-4.54)$ & & $1.30(0.69-2.47)$ & \\
\hline \multicolumn{5}{|l|}{ TNM Stage } \\
\hline Stage 1-3 & Referance & 0.04 & Referance & 0.39 \\
\hline Stage $4 a$ & $2.00(1.02-3.90)$ & & $1.31(0.70-2.44)$ & \\
\hline \multicolumn{5}{|l|}{ Treatment } \\
\hline RT / CRT & Referance & 0.02 & Referance & 0.75 \\
\hline $\begin{array}{l}\text { IND-CRT / CRT- } \\
\text { ADJ }\end{array}$ & $2.23(1.09-4.55)$ & & $1.10(0.59-2.07)$ & \\
\hline \multicolumn{5}{|c|}{ Treatment response } \\
\hline CR & Referance & 0.04 & Referance & 0.25 \\
\hline Non-CR & $3.01(1.05$ - 8.70$)$ & & $1.82(0.64-5.15)$ & \\
\hline
\end{tabular}




\begin{tabular}{|c|c|c|c|c|}
\hline \multirow[b]{3}{*}{ Parameters } & \multirow{2}{*}{\multicolumn{2}{|c|}{$\begin{array}{l}\text { Univariate Analysis } \\
\text { LRRFS }\end{array}$}} & \multirow{2}{*}{\multicolumn{2}{|c|}{$\begin{array}{l}\text { Univariate Analysis } \\
\text { DMFS }\end{array}$}} \\
\hline & & & & \\
\hline & $\begin{array}{l}\text { HR (95\% Cl, Lower - } \\
\text { Upper) }\end{array}$ & $\begin{array}{l}\mathrm{P} \\
\text { value }\end{array}$ & HR (95\% Cl, Lower - Upper) & $P$ value \\
\hline \multicolumn{5}{|c|}{ Pre-treatment PNI } \\
\hline$>50.65$ & Referance & $<0.01$ & Referance & $<0.01$ \\
\hline$\leq 50.65$ & $3.47(1.59-7.59)$ & & $2.69(1.28-5.61)$ & \\
\hline \multicolumn{5}{|c|}{ Post-treatment PNI } \\
\hline$>44.75$ & Referance & 0.06 & Referance & 0.60 \\
\hline \multirow[t]{4}{*}{$\leq 44.75$} & $2.15(0.97-4.75)$ & & $1.24(0.57$ - 2.69) & \\
\hline & Multivariate Analysis & & Multivariate Analysis & \\
\hline & LRRFS & & DMFS & \\
\hline & $\begin{array}{l}\text { HR (95\% Cl, Lower - } \\
\text { Upper) }\end{array}$ & $\begin{array}{l}P \\
\text { value }\end{array}$ & HR (95\% Cl, Lower - Upper) & $P$ value \\
\hline \multicolumn{5}{|c|}{ Pre-treatment PNI } \\
\hline$>50.65$ & Referance & $<0.01$ & Referance & $<0.01$ \\
\hline$\leq 50.65$ & $4.27(1.66-10.93)$ & & $3.34(1.44-7.66)$ & \\
\hline \multicolumn{5}{|c|}{ Post-treatment PNI } \\
\hline$>44.75$ & Referance & 0.98 & Referance & 0.94 \\
\hline$\leq 44.75$ & $0.99(0.38-2.56)$ & & $1.02(0.44-2.36)$ & \\
\hline
\end{tabular}

Table 4. Univariate and multivariate analyses for overall survival. 


\begin{tabular}{|c|c|c|c|c|}
\hline \multirow[b]{2}{*}{ Parameters } & \multicolumn{2}{|l|}{ Univariate Analysis } & \multicolumn{2}{|l|}{ Multivariate Analysis } \\
\hline & $\begin{array}{l}\text { HR ( } 95 \% \text { Cl, Lower - } \\
\text { Upper) }\end{array}$ & $\begin{array}{l}\mathrm{P} \\
\text { value }\end{array}$ & HR (95\% Cl, Lower - Upper) & $P$ value \\
\hline \multicolumn{5}{|l|}{ Age } \\
\hline$\leq 52$ & Referance & $<0.01$ & Referance & 0.96 \\
\hline$>52$ & $2.57(1.39-4.73)$ & & $0.98(0.46-2.07)$ & \\
\hline \multicolumn{5}{|l|}{ Gender } \\
\hline Female & Referance & 0.38 & & \\
\hline Male & $1.37(0.72-2.62)$ & & & \\
\hline \multicolumn{5}{|l|}{ Histologic type } \\
\hline WHO Type $1 \& 2$ & Referance & 0.02 & Referance & 0.94 \\
\hline WHO Type 3 & $0.45(0.23-0.87)$ & & $0.97(0.47-2.01)$ & \\
\hline \multicolumn{5}{|l|}{ T category } \\
\hline T1-2 & Referance & $<0.01$ & Referance & 0.01 \\
\hline T3-4 & $2.95(1.56-5.55)$ & & $3.54(1.48-8.49)$ & \\
\hline \multicolumn{5}{|l|}{$\mathrm{N}$ category } \\
\hline NO-2 & Referance & $<0.01$ & Referance & 0.02 \\
\hline N3 & $2.61(1.44-4.74)$ & & $2.51(1.17-5.38)$ & \\
\hline \multicolumn{5}{|l|}{ TNM Stage } \\
\hline Stage 1-3 & Referance & 0.01 & Referance & 0.41 \\
\hline Stage $4 a$ & $2.21(1.21-4.02)$ & & $0.67(0.27-1.70)$ & \\
\hline \multicolumn{5}{|l|}{ Treatment } \\
\hline RT / CRT & Referance & 0.68 & & \\
\hline $\begin{array}{l}\text { IND-CRT / CRT- } \\
\text { ADJ }\end{array}$ & $0.88(0.49-1.58)$ & & & \\
\hline \multicolumn{5}{|c|}{ Treatment response } \\
\hline $\mathrm{CR}$ & Referance & $<0.01$ & Referance & $<0.01$ \\
\hline Non-CR & $13.21(5.17$ - 33.73) & & $10.87(3.95-29.90)$ & \\
\hline
\end{tabular}




\begin{tabular}{|c|c|c|c|c|}
\hline \multirow[b]{2}{*}{ Parameters } & \multicolumn{2}{|l|}{ Univariate Analysis } & \multicolumn{2}{|l|}{ Multivariate Analysis } \\
\hline & $\begin{array}{l}\text { HR ( } 95 \% \text { Cl, Lower - } \\
\text { Upper) }\end{array}$ & $\begin{array}{l}\mathrm{P} \\
\text { value }\end{array}$ & HR (95\% Cl, Lower - Upper) & $P$ value \\
\hline \multicolumn{5}{|c|}{ Pre-treatment PNI } \\
\hline$>50.65$ & Referance & $<0.01$ & Referance & 0.04 \\
\hline$\leq 50.65$ & $2.63(1.43-4.85)$ & & $2.11(0.98-4.56)$ & \\
\hline \multicolumn{5}{|c|}{ Post-treatment PNI } \\
\hline$>44.75$ & Referance & $<0.01$ & Referance & 0.02 \\
\hline$\leq 44.75$ & $5.52(2.73-11.15)$ & & $2.65(1.18-5.96)$ & \\
\hline
\end{tabular}

\section{Figures}



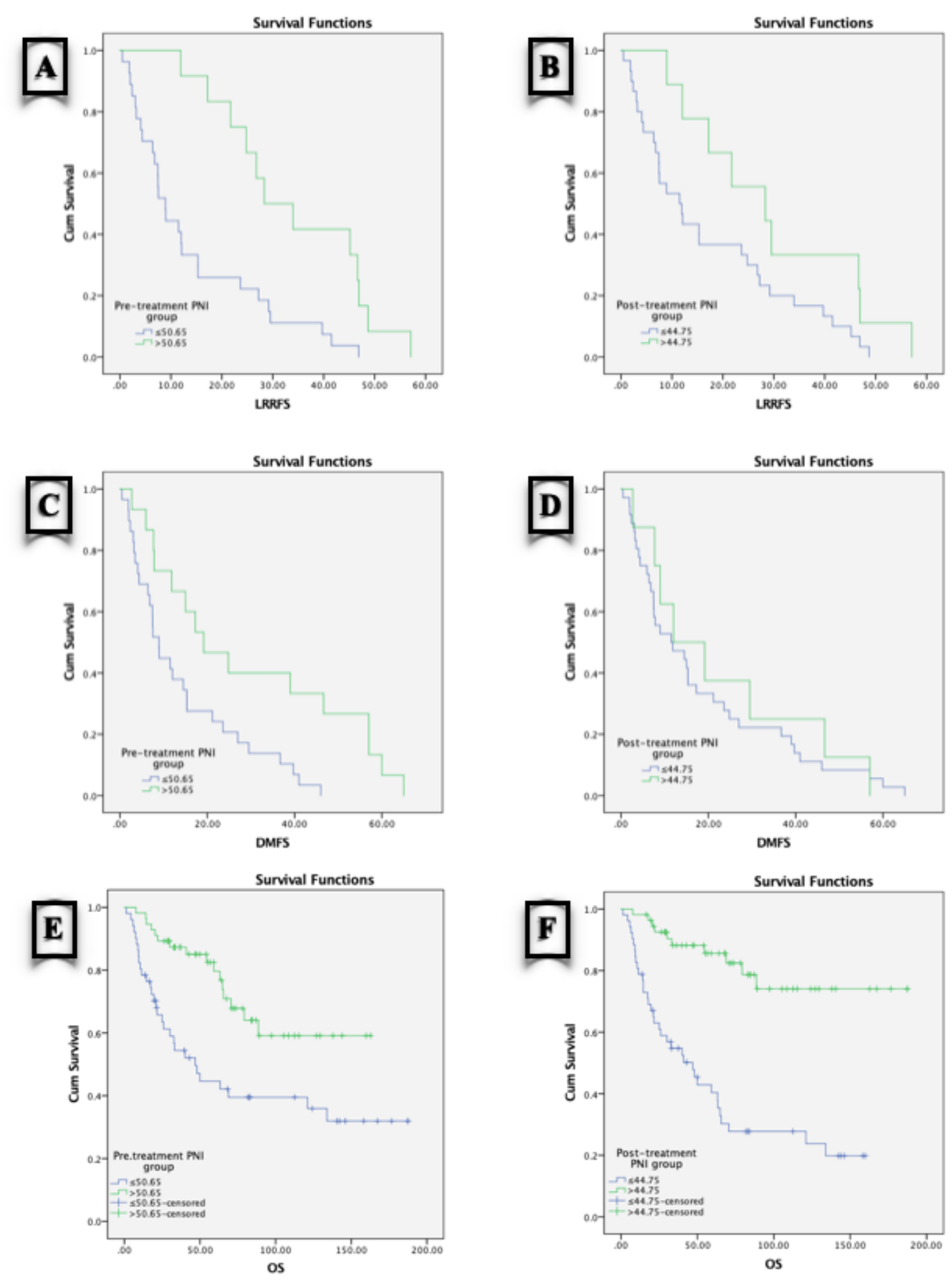

\section{Figure 1}

Kaplan-Meier survival analysis curves for pre- and post-treatment PNI according to the groups (high-low). A. Loco-regional failure-free survival between groups for pre-treatment PNI. B. Loco-regional failure-free survival between groups for post-treatment PNI. C. Distant metastasis-free survival between groups for pre-treatment PNI. D. Distant metastasis-free survival between groups for post-treatment PNI. E. Overall survival between groups for pre-treatment PNI. F. Overall survival between groups for post-treatment PNI. 


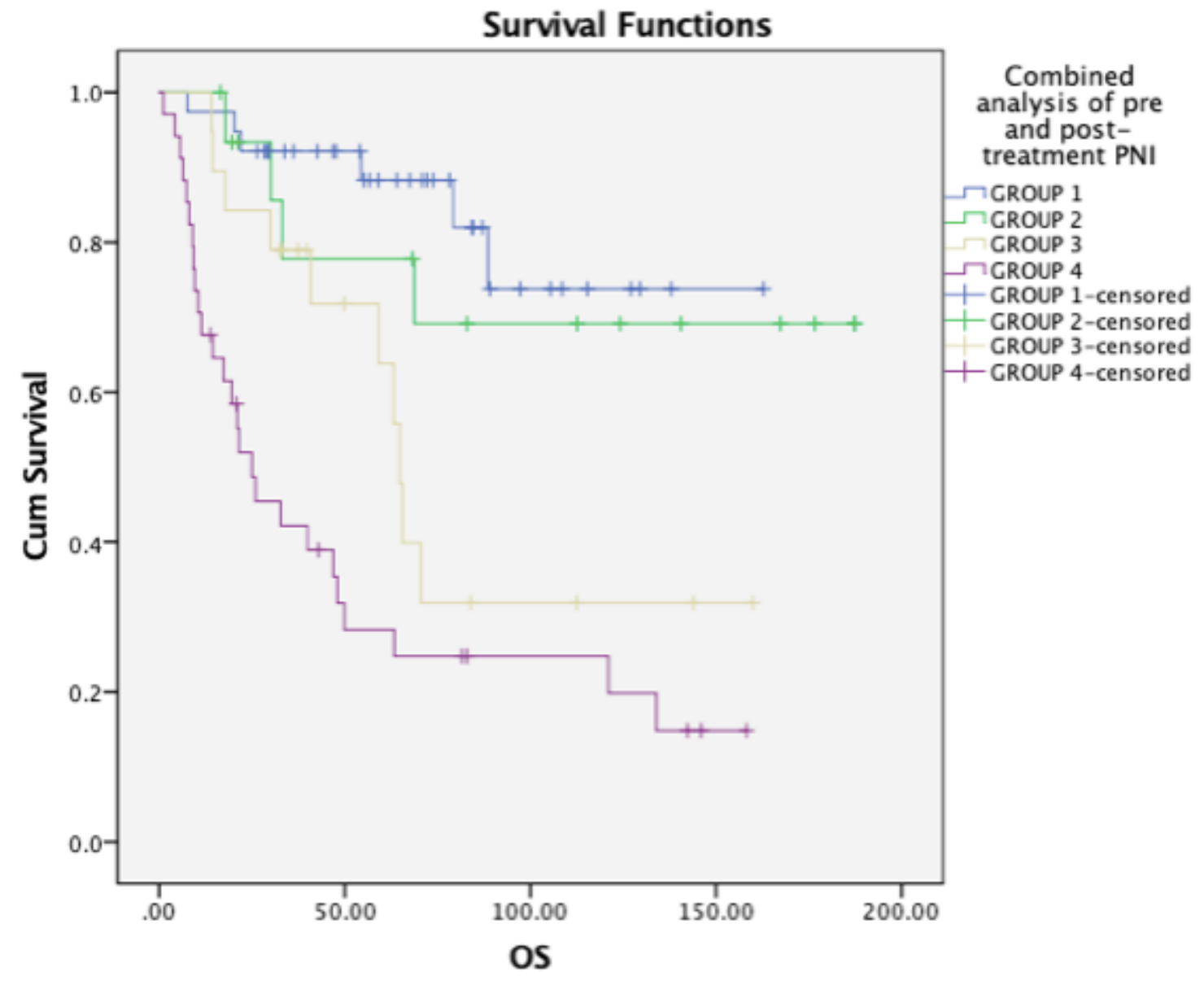

Figure 2

Kaplan-Meier curves for overall survival between prognostic groups according to PNI dynamics. 